\title{
ESTUDO DE CASO DA APLICAÇÃO DE PAINEIS IMAGÉTICOS COMO METODOLOGIA DE PROJETO EM DESIGN DE INTERIORES
}

\author{
Victor Hugo Santos, mestrando \\ Universidade Federal da Bahia - UFBA \\ victorcarvalhoarq@gmail.com \\ Maria Herminia Hernandez, Dra \\ Universidade Federal da Bahia - UFBA \\ herminia234@yahoo.com.br
}

Resumo: Esta pesquisa explora o papel dos exercícios conceituais no decorrer do processo metodológico de criação do designer de interiores. Tem por objetivo observar a aplicação de atividades projetuais, voltadas para a criatividade e inovação na fase de pré-projeto e como estas aplicações interferem no desenvolvimento das etapas seguintes do projeto básico. Desta forma, apresenta-se a aplicação dos painéis imagéticos na disciplina de Desenvolvimento do Projeto de Decoração Ambiental IV do curso Superior de Decoração da Escola de Belas Artes da Universidade Federal da Bahia no semestre 2015.1. Com base nos resultados, o texto mostra a importância da abordagem com foco nos aspectos conceituais, considerando, portanto, a relevância daqueles para o trabalho do designer e suas tomadas de decisão.

Palavras-chave: metodologia de projeto, processos em design, design conceitual, conceito projetual.

\begin{abstract}
This research explores the role of conceptual exercises during the interior design methodological creation process. It has the purpose to observe the application of activities in the project, focusing on creativity and innovation at the pre-project phase and how these applications interfere within the development of the following stages of the basic project. In that way, it presents the use of imagetic panels in the discipline 'Development of Environmental Decoration Project IV' on the Decoration Master's Degree Course at Fine Arts School of Federal University of Bahia, in the 2015.1 term. Based on the outcomes, the text shows the importance of the approach focused on conceptual aspects, taking into account, therefore, the relevance of those in the designer's work and their decisionmakings.
\end{abstract}

Keyword: project methodology, design processes, concept design, project concept 


\section{INTRODUÇÃO}

Projetar espaços internos requer do designer diversas técnicas de registro para a materialização de uma ideia, geralmente parte-se de um problema em direção a uma solução, o caminho percorrido para sair de um ponto a outro é escolhido pelo profissional encarregado a tarefa, ou indicado pelo professor responsável da disciplina de projeto no caso dos estudantes. Impreterivelmente o designer de interiores passa neste percurso pela representação gráfica de suas ideias, por meio de croquis, elevações, plantas, detalhamentos, vistas, cortes, entre outras formas de desenho e de apresentação, afim de materializar um plano para a execução de sua proposição.

Nota-se, porém, que a fase de conceptualização do projeto é pouco assistida ou deixada de lado, uma vez que atualmente existe uma pratica muito focada nas peças de desenho técnico e pouca ou nenhuma aproximação com as problemáticas do contexto de projeto e com as necessidades e desejos dos usuários envolvidos, muitos projetos acabam assim, sendo guiados pelo arcabouço pessoal do designer.

Deve-se ter em mente que as peças técnicas são informações cruciais para a execução do projeto, porem podem ser executadas por técnicos e desenhistas especializados na reprodução gráfica, mas a ideia de solução, a conceptualização, parte do designer, devendo esta ser a peça chave do projeto.

Para o início desta conceptualização é necessário que as aproximações e delimitações da problemática sejam etapas bem executadas, se tornando decisivas para a criação de uma base que suporte o desenvolvimento do projeto. Uma das melhores formas de se construir parte desta fundação é através dos diálogos entre o designer e cliente/usuário do espaço, não estamos falando apenas dos levantamentos feitos através dos questionários escritos, os chamados briefings ${ }^{1}$, que são aplicados seguindo formalmente uma série de perguntas, muitas vezes deixadas de lado no decorrer do projeto, mas de uma metodologia que auxilie na sintonia entre as partes.

Estamos propondo um estudo de caso do uso de uma metodologia que possa melhorar a interlocução entre os principais envolvidos do processo criativo, sugerindo o uso de painéis imagéticos, compostos por interpretações do designer frente a sua percepção das aproximações com as necessidades do seu cliente/usuário e com as problemáticas em questão.

Sugerindo, portanto, um exercício prático executado pelos alunos da disciplina de Desenvolvimento do Projeto de Decoração IV do curso de Design de Interiores da Escola de Belas Artes EBA/UFBA. Afim de verificar de que maneira o uso dos painéis podem contribuir para o desenvolvimento de projeto.

\section{DESENVOLVIMENTO}

A atividade projetual do designer está ligada a expressão de soluções para determinadas problemáticas, a execução desta tarefa implica no uso prático de metodologias que irão nortear o processo de criação. Estas, podem variar de acordo com o campo e o foco de aplicação, já que o design pode se desdobrar em diversas especialidades, como o de moda, mobiliário, gráfico, dentre outros.

\footnotetext{
${ }^{1}$ Segundo dicionário Michaelis briefing significa: instrução ou informação essencial. Disponível em: < http://michaelis.uol.com.br/moderno/ingles/index.php?lingua=ingles-portugues\&palavra=briefing $>$. Acessado dia 01 de Maio de 2016.
} 
Neste artigo abordaremos o estudo de caso da aplicação de um exercício metodológico de painéis conceituais para estudantes de Design de Interiores, entendendo-se está como:

(...) uma prática interdisciplinar que se ocupa da requalificação do espaço na medida em que o adequa a uma nova identidade. Todavia, trata de outra dimensão de intervenção, pois aborda uma (re) definição conceitual/estética dos interiores, numa manipulação do volume espacial a partir do tratamento de superfícies, da iluminação, da escolha de materiais fixos e móveis. (DUARTE et al.,2012, p. 8743)

A definição acima evoca o significado das definições conceituais para o exercício projetual do designer de interiores, porém, muitas das práticas em projeto, conforme já colocado, se voltam para as questões técnicas de representação. Tanto na academia quanto no mercado, na maioria das vezes, se valoriza mais o produto final composto pelas peças executivas, causando um déficit na formação de uma linguagem subjetiva e criativa de conceptualização projetual.

Esta linguagem subjetiva parte da criação de um conceito, que irá direcionar as demais escolhas efetuadas no decorrer do processo. É nesta fase onde ocorre a materialização do imaterial, onde os conceitos buscam meios de se comunicar, e assim "através da forma buscam converter a expressão subjetiva em comunicação objetivada" (OSTROWER, 2010, p.24).

De acordo com Frazato (2012, p. 226) este ato de concepção "é geralmente entendido como um output intermediário do processo criativo" é nesta fase que se dá força ao projeto, de onde saem as ideias inovadoras e únicas como corrobora Travis (2011).

Assumimos que "é necessário entrar na complexidade da constatação de que criação é um ato comunicativo" (SALLES, 2013, p. 49), e a fase de conceptualização projetual é crucial tanto na explanação entre designer/cliente e designer/equipe, quanto na fomentação intelectual do estudante na academia.

A metodologia que busca ser aplicada é a dos painéis imagéticos, através deles muitos profissionais desenvolvem uma linguagem universal, afim de criar estímulos, despertar emoções, gerar evocações, veicular mensagens e provocar reflexões como afirma Norman (2008).

Os painéis conceituais geralmente são utilizados em concursos, exposições e publicações porem "não impede que estes concepts sejam desenvolvidos tecnicamente e efetivamente editados" (FRANZATO, 2012, p. 227). Neste processo além de serem discutidos aspectos formais e funcionais os "valores simbólicos agregados a ele devem ser coerentes, um dado importante é provocar a sua sensibilização e aceitação natural" (SOUZA, 2010, p. 3).

Portanto na base destas reflexões, se torna importante o discurso em torno de novos métodos que estimulem a comunicação subjetiva do estudante, e que ajudem na comunicação de sua ideia com futuros clientes, equipe de projeto e tutores docentes em sala, afim de que este perceba, por meio da criação do seu conceito, como as definições iniciais de aproximação contribuem efetivamente para o desenvolvimento das fases seguintes do projeto e para as tomadas de decisão. 


\subsection{PROPOSTA}

O objetivo principal do exercício é de realizar uma proposta projetual para ambientes de uso comercial e/ou de serviços que como parte da metodologia de abordagem, desenvolva em profundidade os aspectos conceituais, considerando a relevância daqueles para o trabalho do design e suas tomadas de decisão.

Para o desenvolvimento e aplicação da metodologia específica foram escolhidos três ambientes da Escola de Belas Artes: área posterior à Galeria Cañizares, Biblioteca e edifício anexo do Programa de Pós-Graduação. Consideramos para a prática os espaços internos das edificações e seus entornos imediatos para que os grupos desenvolvessem esta relação em exercício, a serem trabalhados por três Grupos, integrados pelos estudantes da turma.

\subsubsection{ETAPA №1: APROXIMAÇÕES}

No intuito de se aproximar do Contexto e da elaboração do programa, o estudante desenvolverá atividades que se baseiem nos princípios de aproximação abordados por Travis (2011). Serão eles:

1. Aproximação com o espaço / contexto.

Lugar: Como as prioridades existentes se manifestam nas primeiras impressões? Qual a percepção do espaço?

Construção: Como se comportam as ligações entre o espaço e a arquitetura que o comporta ou a cerca?

História: Qual a história do sitio, seus usos e elementos que necessitem de restauro?

2. Briefing.

Função ou programa: Qual o uso que o espaço pretende ter e quais ele demonstra necessitar?

Cliente: Caracterizar o usuário do espaço, individual ou coletivo? Quais os desejos e necessidades que estes expressam?

Material a ser entregue;

Dois painéis em formato A-2 ou A-3. Sendo um, acerca das aproximações com o espaço/contexto e outro sobre o briefing. Estes painéis devem conter observações pertinentes sobre o espaço, como deficiências e aspectos importantes sobre sua envoltória. Deve conter planta de cadastros com linhas de chamada e croquis. A apresentação dos mesmos será oral com entrega dos materiais produzidos.

\subsubsection{ETAPA №2: CRIAÇÃO DOS PAINEIS IMAGÉTICOS (ARQUETÉTIPO E SEMÂNTICO)}

O estudante elaborará os painéis Arquétipo e Semântico, atendendo à especificidade de cada um.

1. Painel Arquétipo

A teoria dos arquétipos foi desenvolvida por Carl Gustav Jung e apresentada pela primeira vez em um simpósio em Londres intitulado "Instinto e Inconsciente" em 1919. Este termo já tinha sido conhecido pela filosofia através de Platão para designar as ideias como modelos de todas as coisas existentes, porém de acordo com Hall \& Nordby (2014) Jung em sua concepção aborda os arquétipos como conteúdo do inconsciente, herdados e universais, que representam padrões de comportamento e de personalidade. 
O painel deve, portanto, transmitir através de imagens uma leitura inicial da personalidade do cliente e ou usuários do espaço, neste o estudante deve buscar por meio de imagens se aproximar dos padrões de comportamento e de identidade dos usuários.

2. Painel Semântico

Registra as imagens que servirão de inspiração para a elaboração do projeto. Estas devem transmitir o estimulo ou a atmosfera que o espaço irá causar aos seus usuários.

Material a ser entregue;

Dois painéis em formato A-2 ou A-3. Sendo um Arquétipo e outro o Semântico. A apresentação dos mesmos será oral com entrega dos materiais produzidos.

\subsubsection{ETAPA №3: CRIAÇÃO DOS PAINEIS IMAGÉTICOS (CONCEPT BOARD E COORDENAÇÃO) E PRANCHAS TÉCNICAS DO PROJETO}

O estudante elaborará os painéis Concept board e Coordenação e pranchas de projeto (lay-out, vista, corte e perspectiva).

1. Concept board

O painel tem derivação nos aspectos subjetivos desenvolvidos nos painéis arquétipos e semânticos, objetivando a ideia do conceito através das principais linhas e formas escolhidas para o projeto.

2. Painel Coordenação

Ancorado também nas definições previas dos painéis arquétipo e semântico, registra as cores e texturas que irão compor o projeto.

3. Pranchas Técnicas:

Planta de lay-out, vista (1) e Corte (1) e perspectiva. A escala dos desenhos será definida para cada objeto

Material a ser entregue;

Dois painéis em formato A-2 ou A-3. Sendo um Concep board e Coordenação As pranchas (podem ser em auto-cad ou a mão), seguindo as normas técnicas de desenho.

\subsection{RESULTADOS}

Após apresentação de aula expositiva com a proposta para o exercício, os alunos levantaram perguntas quanto aos painéis e a estrutura dos mesmos, alguns sentiram dificuldade em distinguir a diferença entre os painéis arquétipo e semântico, entendemos que a dificuldade reside em um resultado positivo, já que os estudantes enxergam no conceito atmosférico do espaço similaridade ao perfil de personalidade dos seus usuários. Após aula de discussões, os espaços foram visitados para levantamento das questões mais latentes quanto a segurança e a estrutura espacial mínima necessária para as atividades contidas no programa, ao passo que realizavam um cadastro físico anotando os demais aspectos percebidos.

Em outro encontro os estudantes puderam entrevistar a diretoria da escola, que forneceu informações relevantes quanto aos aspectos históricos e de conservação dos espaços propostos para o exercício, bem como, ideias e desejos que possuíam para os projetos. Com este primeiro material do contexto composto pelas percepções históricas, espaciais e de briefing, produziram os dois primeiros painéis do exercício. 
Neste artigo utilizaremos o material produzido em especifico pela primeira equipe responsável pelo projeto de uma cantina para a área posterior a Galeria Cañizares, demonstrada nas imagens 01 e 02, porém buscaremos também trazer as impressões gerais de todos os grupos.
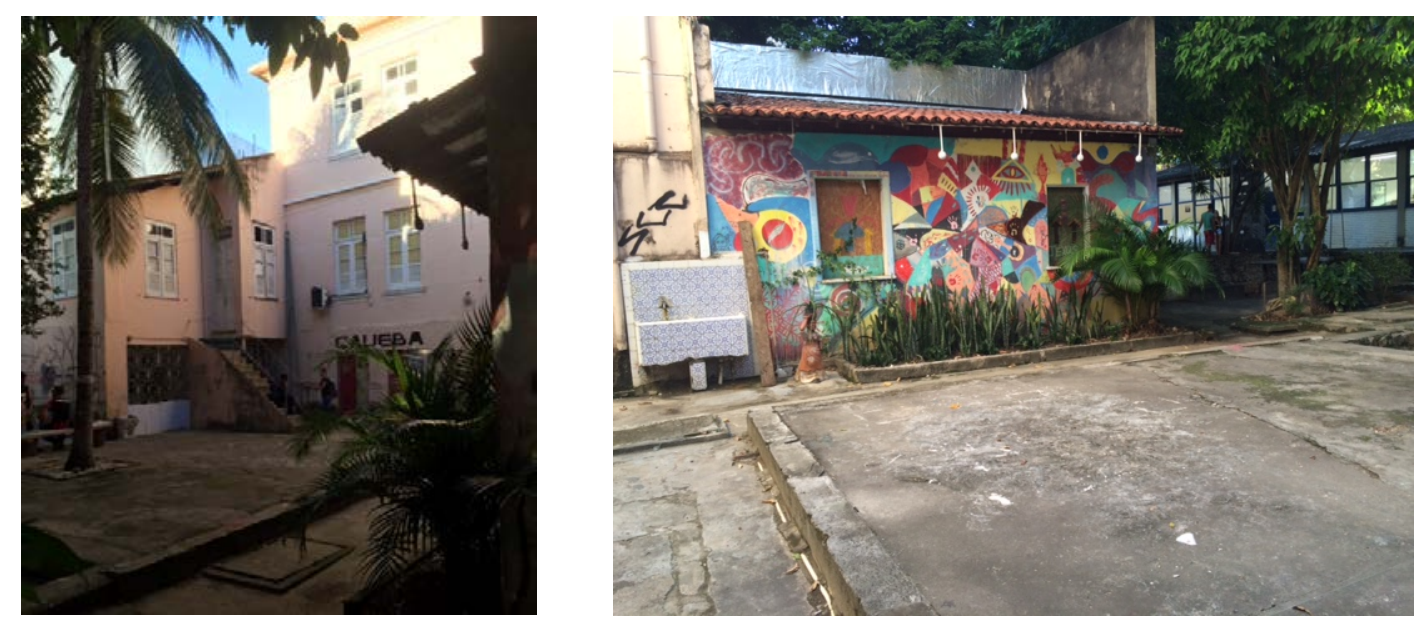

Figuras 01 e 02 - Fotografias da área posterior a Galeria Cañizares destinada ao projeto da cantina. Fonte: Elaborada pelo autor, com base na pesquisa realizada.

Percebemos na equipe, a necessidade que suas integrantes tiveram em ampliar o entendimento dos contextos espaciais, procurando conhecer um pouco mais sobre o entorno urbano em que o ambiente se encontra, propondo uma relação entre a escola e o circuito sociocultural de seu entorno, buscando conceitos de como a cantina poderia ser além do espaço de convivência dos estudantes e funcionários da escola, um ponto nodal do entorno composto por edificações e locais de fortes atividades artísticas e culturais, como: a Galeria Cañizares (da própria escola) o Teatro Martim Gonçalves da Escola de Teatro da UFBA, Teatro Castro Alves (TCA), o Largo do Campo Grande, conhecido como Praça 2 de Julho e a rede de museus próximos, entre outros, como demonstrado nas imagens 03 e 04.

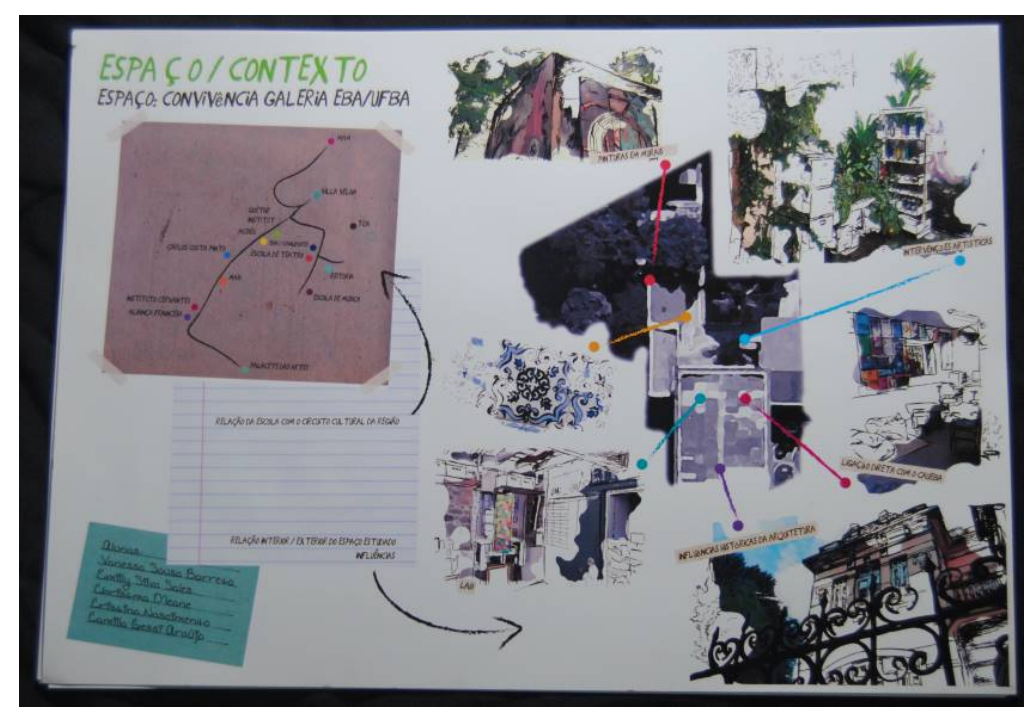

Figuras 03 - Fotografias do painel de contexto da equipe 01.

Fonte: Elaborada pelo autor, com base na pesquisa realizada. 


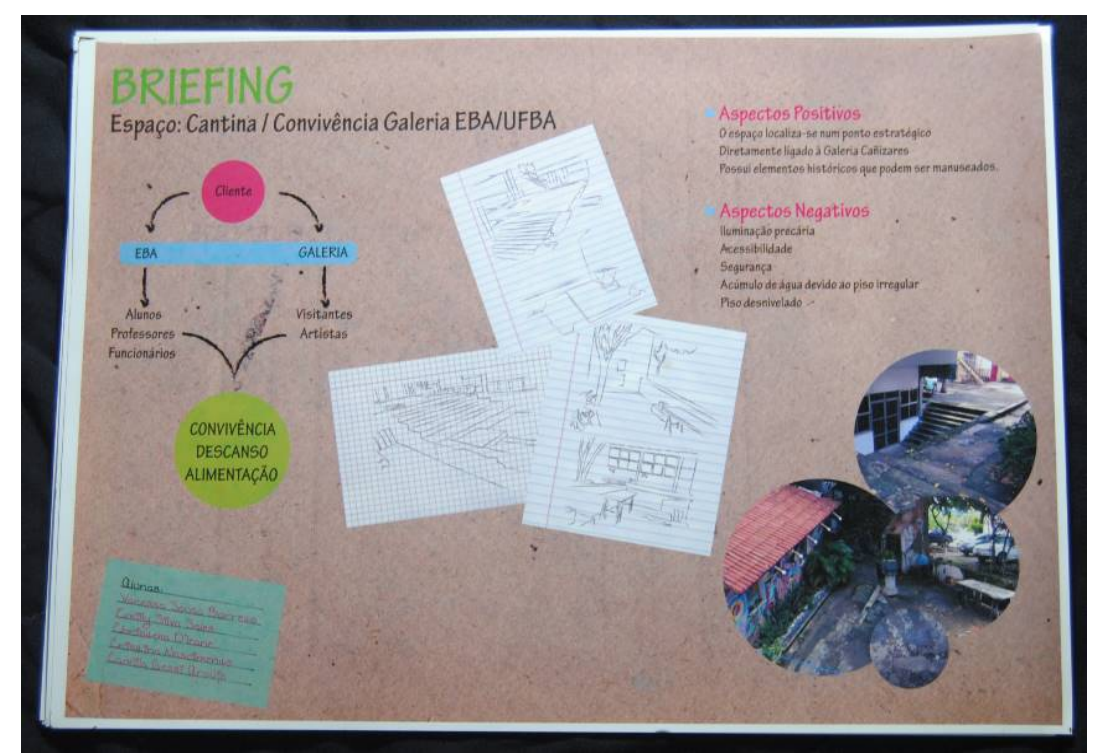

Figuras 04 - Fotografias do painel de briefing da equipe 01.

Fonte: Elaborada pelo autor, com base na pesquisa realizada.

As abordagens iniciais levantaram aspectos interessantes, como a maneira que cada estudante escolheu para uma aproximação com o contexto, por mais que a metodologia sugerisse um direcionamento, cada equipe se aproximou da temática de maneira particular. Após as apresentações e compartilhamentos das equipes os primeiros grupos procuraram aplicar os mesmos questionários utilizados pelas equipes finais aos estudantes que passavam pela área, tentando compreender o seu perfil e personalidade, observando os padrões que pudessem compor os painéis imagéticos arquétipo e semântico.

Para o terceiro encontro foi sugerido que os estudantes trouxessem revistas, afim de que produzissem as primeiras montagens dos painéis em sala, podendo receber supervisão e tirar dúvidas com os professores em relação a sua composição e conceitos centrais, a figura 05 retrata as estudantes realizando conexões e separando as imagens em grupos conceituais. Neste encontro, foi identificada certa dificuldade inicial, já que se tratava de uma metodologia nova, os estudantes enfrentavam adversidades principalmente na escolha e composição de imagens que sugerissem e representassem suas impressões e ideias.

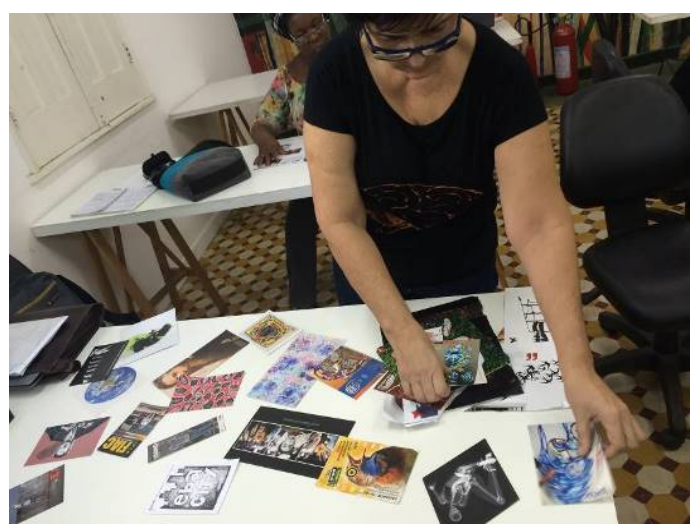

Figuras 05 - Fotografia das estudantes em sala realizando o agrupamento de imagens.

Fonte: Elaborada pelo autor, com base na pesquisa realizada. 
Todos os grupos optaram em seguida, pela digitalização de alguns recortes e recorreram a um banco de imagens on-line para compor melhor suas escolhas. A primeira equipe levantou um questionamento interessante em relação à construção do painel arquétipo, pontuando sua dificuldade em representar imageticamente a personalidade de um grupo, ressaltando que procuraram ser o mais generalista possível para não dar margem a uma rotulação de padrões comportamentais que representassem indivíduos ao invés do grupo. Incluíram no painel, portanto, símbolos que relatassem os diferentes usuários que teriam contato com o espaço como demonstrado na imagem 06.

No segundo painel, apresentado pela imagem 07, as integrantes optaram por imagens que possuíssem significados objetivos que confeririam a ideia de leveza e relaxamento a atmosfera, através das paisagens tranquilas e penas de animais, bem como utilizaram imagens mais subjetivas como de uma pantera, que ressaltasse a importância da agilidade e versatilidade que almejavam para o projeto. Utilizaram também uma figura mais abstrata composta por um emaranhado de linhas, afim de que pudessem transmitir uma ideia de conexão entre as partes do painel.

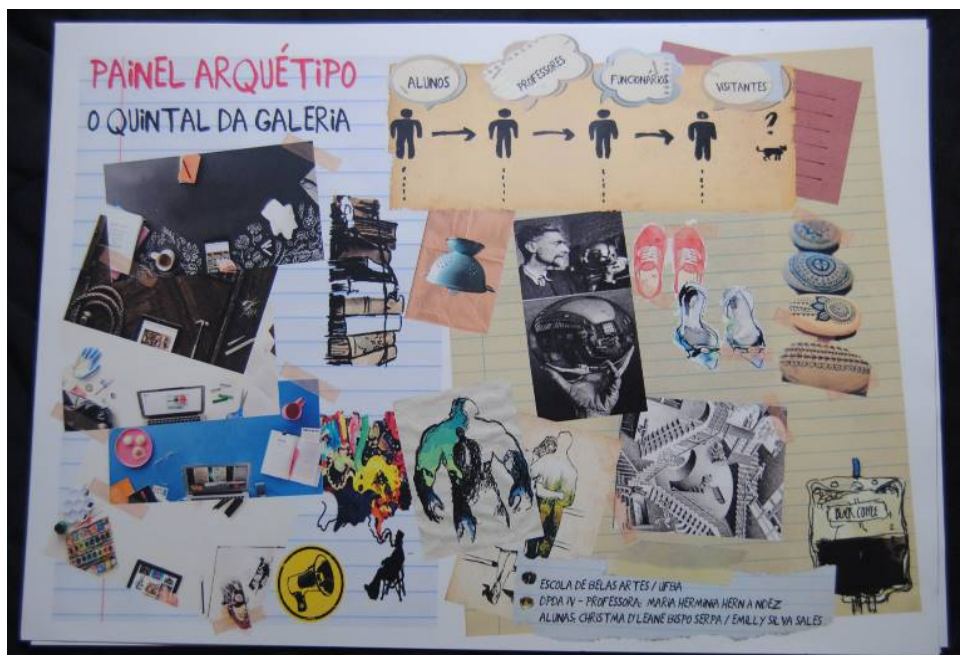

Figuras 06 - Fotografias do painel arquétipo da equipe 01.

Fonte: Elaborada pelo autor, com base na pesquisa realizada.

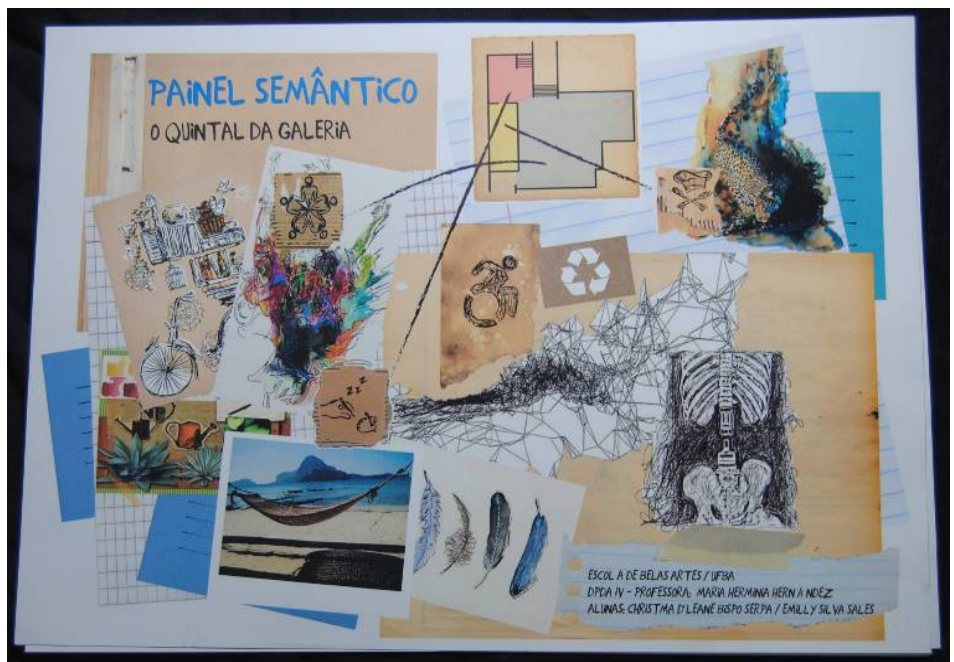

Figuras 07 - Fotografias do painel semântico da equipe 01.

Fonte: Elaborada pelo autor, com base na pesquisa realizada. 
Após as apresentações e as discussões, os grupos partiram para a produção dos painéis de conceito e de coordenação, que já trariam uma planta baixa com a ideia de como os conceitos desenvolvidos dos dois primeiros painéis seriam refletidos nas escolhas das linhas, formas, cores e texturas do espaço.

A primeira equipe resgatou no primeiro painel a ideia de moveis de design minimalista que não representassem um estilo determinado, respeitando a multiplicidade de opiniões e personalidades, conceito reforçado também pela diversidade cromática escolhida para o mobiliário. A maioria das peças seriam recicladas e produzidas na própria escola com o auxílio dos professores de outras disciplinas, este mobiliário não seria fixo, conferindo dinâmica e fluidez ao espaço, que poderia se configurar de acordo com a necessidade momentânea, ilustrados nas imagens 08 e 09, as estudantes também intitularam a área como Quintal da EBA reforçando o conceito impessoal e aconchegante que propunham para o espaço.

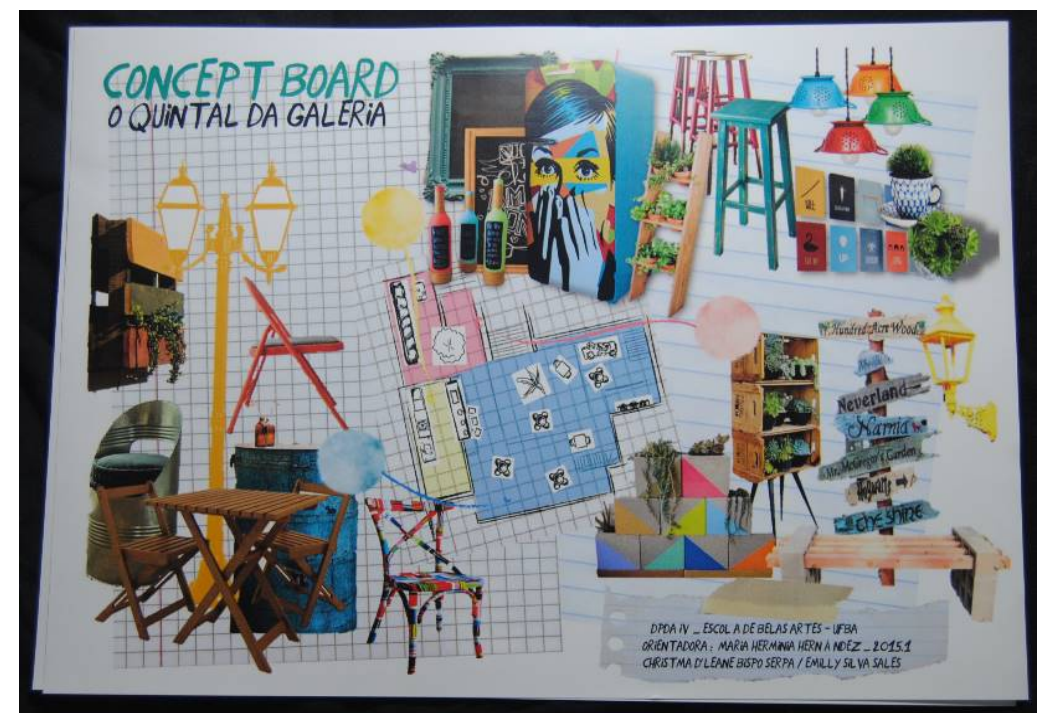

Figuras 08 - Fotografias do concept board da equipe 01.

Fonte: Elaborada pelo autor, com base na pesquisa realizada.

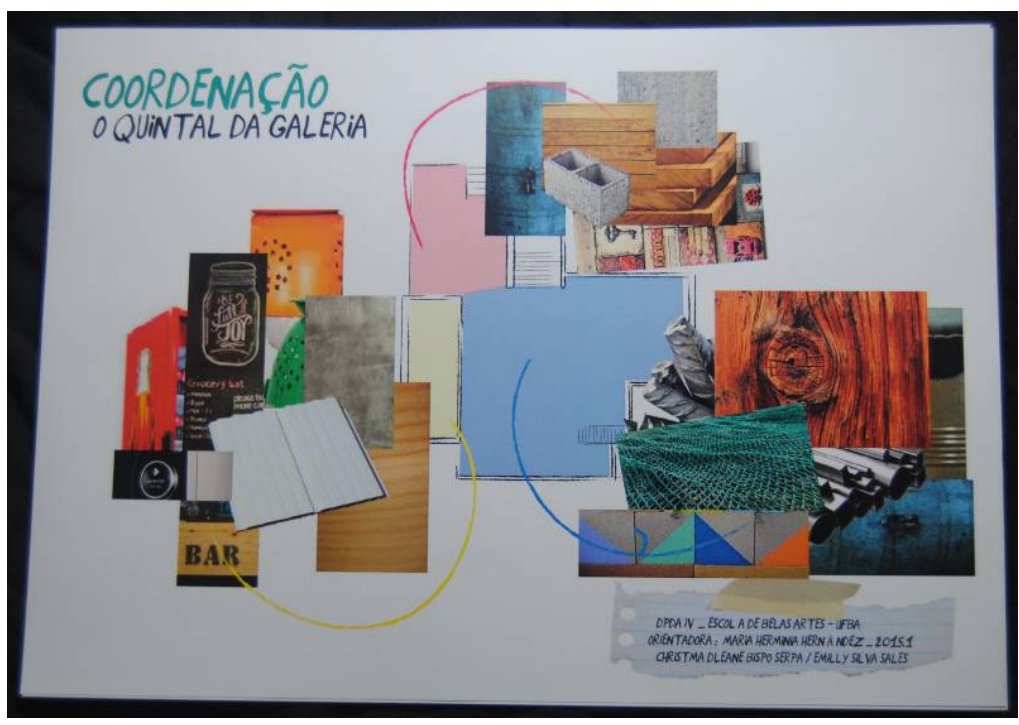

Figuras 09 - Fotografias do painel de coordenação da equipe 01.

Fonte: Elaborada pelo autor, com base na pesquisa realizada. 
Após as entregas e correções, as estudantes tiveram pouco mais de 10 dias para a produção das plantas baixas, perspectivas e cortes, devido ao pouco tempo restante para as entregas imaginou-se que as representações seriam básicas e que não restaria tempo para uma produção técnica aprofundada, mas alguns grupos relataram a facilidade no desenvolvimento destas etapas, produzindo plantas técnicas executivas, inclusive das instalações hidráulicas e elétricas, outros painéis de memorial descritivo, além de protótipos para a entrega final de projeto, como demostra a caixa para a entrega feita pela equipe em imagem 10 e 11.

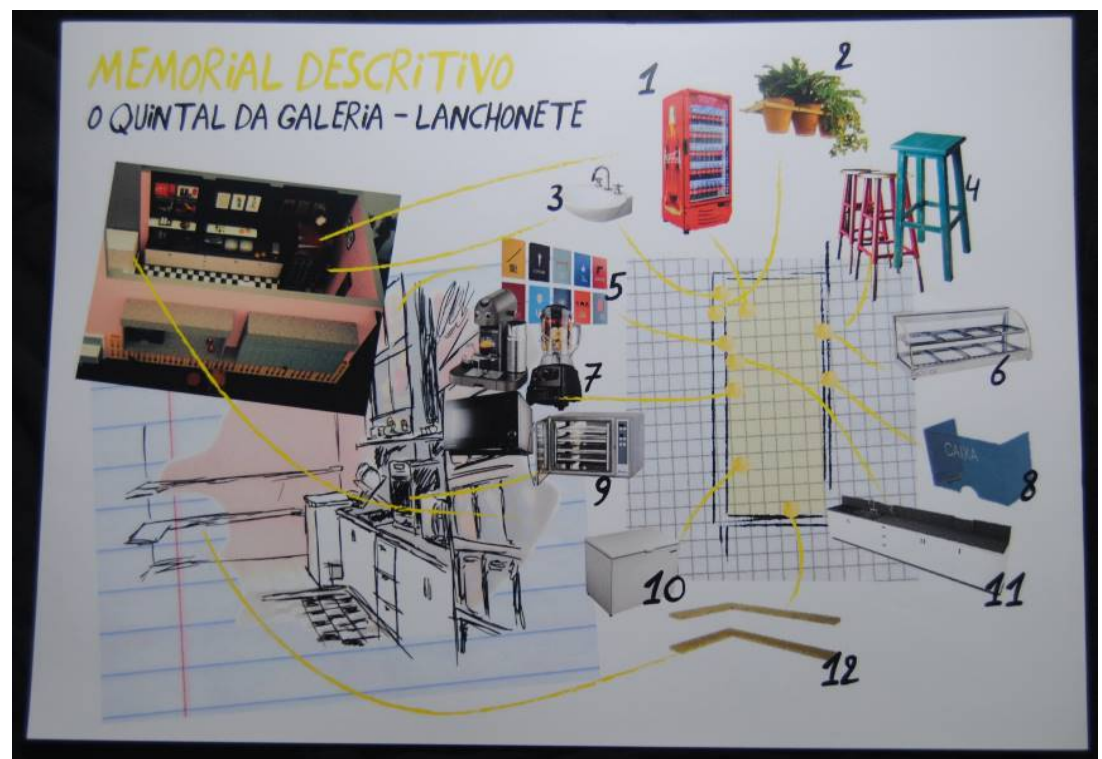

Figuras 10 - Fotografias de um dos painéis do memorial descritivo da equipe 01. Fonte: Elaborada pelo autor, com base na pesquisa realizada.

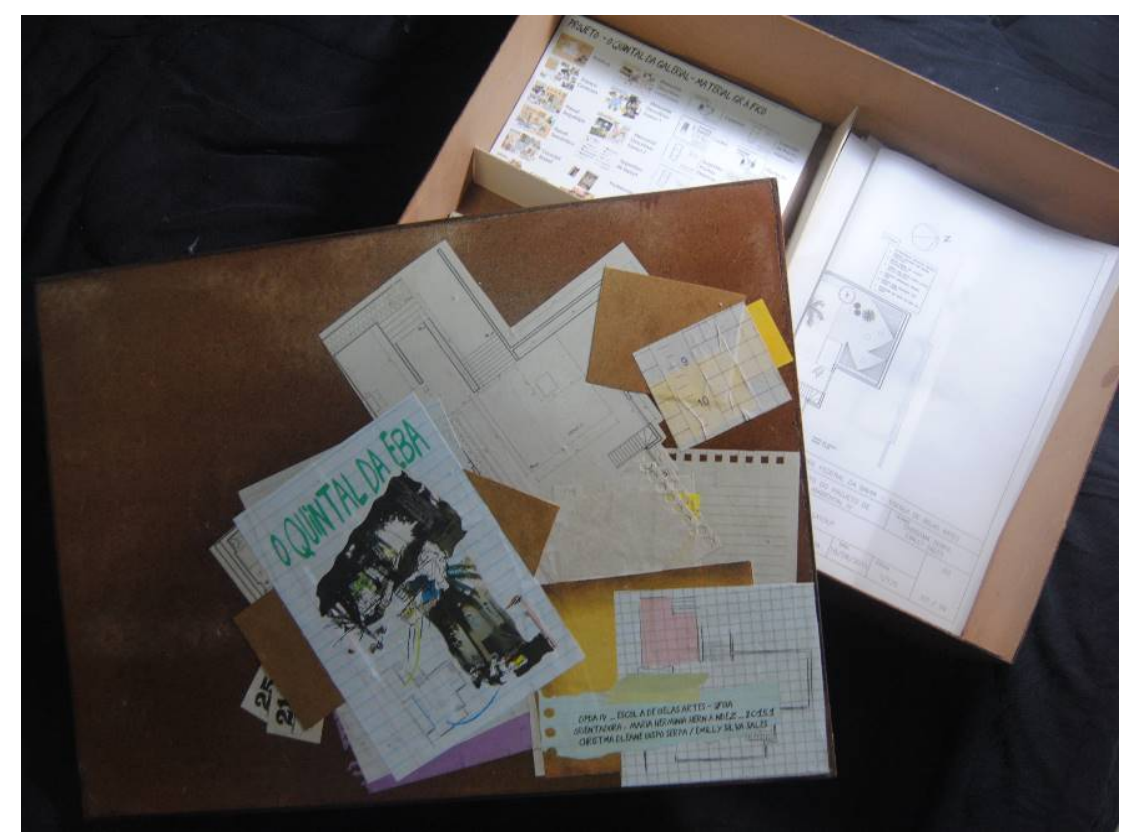

Figuras 11 - Fotografias de um dos painéis do memorial descritivo da equipe 01. Fonte: Elaborada pelo autor, com base na pesquisa realizada. 


\section{CONSIDERAÇÕES}

Considera-se que, de forma geral, os resultados obtidos a partir da experiência aqui descrita deixaram um saldo bastante positivo. Os estudantes envolvidos no exercício de aplicação dos painéis imagéticos consideraram o processo além de interessante, aberto, trazendo a possibilidade de mais interação na construção das idéias voltadas às propostas na fase de pré-projeto. Os envolvidos na realização dos painéis cumpriram todas as etapas programadas, mostrando-se receptivos a essas novas idéias, ao desafio e ao vinculo com vivencias que estimulem o crescimento e formação, muitos inclusive superaram as expectativas quanto às finalizações do material a ser entregue. Desta forma pode-se considerar que os exercícios conceituais baseados nos painéis imagéticos, aplicados como abordagem metodológica no decorrer do processo projetual do designer de interiores de fato contribuíram para uma melhor sistematização das informações, reduzindo incertezas, aumentando proporcionalmente a qualidade do trabalho e favorecendo a interdisciplinaridade e integração. Além disso, o processo resultou em soluções criativas e instigantes.

Notou-se, porém, nos inícios da prática certas dificuldades, voltadas basicamente para a distinção entre o que seria o painel arquétipo e o semântico e ao conteúdo e estrutura dos painéis, situação está considerada normal na aplicação do exercício e positivo na medida em que suscita a reflexão e discussão. Foi verificada, também a tendência de se querer avançar de maneira precoce na realização de peças gráficas apontando possíveis soluções. Neste sentido, sugere-se ser interessante o desenvolvimento e/ ou aplicações mais freqüentes da metodologia em exercícios projetuais acadêmicos de modo a se obter confiabilidade e desenvolvimento de técnicas compatíveis passíveis de compartilhamento. Dessa forma, as oportunidades para o designer de interiores tenderão a abranger programas de trabalho mais ampliados de atuação, a partir de uma abordagem que focada nos aspectos conceituais, configura-se em relevante para o trabalho do designer e suas tomadas de decisão.

\section{REFERÊNCIAS}

BACHELARD, Gaston. A Poética do Espaço. São Paulo: Abril Cultural, 1974.

FRANZATO, Carlo. A forma das ideias. Concept Design e Design Conceitual. In: Congresso Internacional da Associação de Pesquisadores em Críticas Genética, $X$ Edição, 2012.

HALL, Calvin S. \& NORDBY, Vernon J. Introdução à psicologia junguiana. Tradução de Heloysa de Lima Dantas. São Paulo: Cultrix, 2014.

NORMAN, Donald A. Design emocional: porque adoramos (ou detestamos) os objetos do dia-a-dia. Rio de Janeiro: Rocco, 2008.

OSTROWER, Fayga. Criatividade e processos de criação. Petrópolis: Vozes, 2010.

TRAVIS, Stephanie. Conceptual Thinking: The Design Concept in Interior Design

Education. In: Design Principles \& Practices an Internacional Jornal, v. 5, n. 6, p. 679694, 2011. 